\title{
Comparison between two different neuromuscular electrical stimulation protocols for the treatment of female stress urinary incontinence: a randomized controlled trial
}

Comparação de diferentes procedimentos de estimulação elétrica neuromuscular utilizados no tratamento da incontinência urinária de esforço feminina: ensaio clínico randomizado

Priscila G. J. M. Alves', Fabiana R. Nunes², Elaine C. O. Guirro 3

\begin{abstract}
Background: Neuromuscular electrical stimulation (NMES) is widely treatment for stress urinary incontinence (SUI) but there is no consensus in literature regarding the most effective treatment parameters. Objective: To compare two NMESintra-vaginal protocols for the treatment of SUI in women. Methods: The study included 20 volunteers with an average age of $55.55 \pm 6.51$ years and with the clinical diagnosis of SUI. Volunteers were randomly divided into two groups: group 1 (G1) received NMES with medium-frequency current and group 2 (G2) received NMES with low-frequency current. Functional assessments of pelvic floor muscles (PFM) were performed by perineometry. The severity of signs and symptoms were objectively evaluated using the 1 hour pad test and subjectively evaluated using a visual analog scale that measured the discomfort caused by the SUI. Shapiro-Wilk test was used to analyze data normality, and the Friedman test was used to analyze nonparametric data. For analysis of symptoms related to SUI the Fisher exact test and the MannWhitney test were used. Significance level of $5 \%$ was set for all data analysis. Results: No significant differences ( $p>0.05)$ were found between groups for any of the variable assessed. The within group analysis of initial and final evaluations (after NMES) demonstrated significant differences $(p<0.05)$ in amount of urine lost, the discomfort caused by urinary incontinence and perineal pressure for both treatment groups. Conclusion: The two NMES protocols applied were equally effective in the treatment of SUI. Article registered in the Australian New Zealand Clinical Trials Registry (ANZCTR) under number ACTRN 12610000820000.
\end{abstract}

Keywords: urinary incontinence, stress; electrical stimulation; woman's health; physical therapy; rehabilitation.

\section{Resumo}

Contextualização: A estimulação elétrica neuromuscular (EENM) é amplamente utilizada no tratamento da incontinência urinária de esforço (IUE), no entanto não há consenso na literatura sobre os parâmetros de tratamento mais eficazes. Objetivo: Avaliar os procedimentos de EENM intravaginal no tratamento de mulheres com IUE. Métodos: Participaram do estudo 20 voluntárias com idade média de 55,55 $\pm 6,51$ anos, com diagnóstico clínico de IUE. As voluntárias foram divididas aleatoriamente em dois grupos: grupo 1 (G1), que recebeu EENM com corrente de média frequência, e grupo 2 (G2), com corrente de baixa frequência. A avaliação funcional dos músculos do assoalho pélvico (MAP) foi realizada por meio de perineometria, e a severidade dos sinais e sintomas da IUE foi avaliada, objetivamente, pelo pad test de uma hora e, subjetivamente, pela Escala Visual Analógica (EVA), que mediu o desconforto causado pela incontinência. Para a análise de normalidade dos dados, utilizou-se o teste Shapiro-Wilk, seguido do teste de Friedman para dados não paramétricos. Para a análise dos sintomas relacionados à IUE, usaram-se os testes Exato de Fisher e Mann-Whitney. Em todas as análises, considerou-se o nível de significância de 5\%. Resultados: Não houve diferença significativa ( $p>0,05)$ entre os grupos em nenhuma variável avaliada. Na comparação intragrupos das avaliações iniciais e finais (após EENM), houve diferença significativa $(p<0,05)$ na quantidade de urina perdida, no desconforto causado pela incontinência urinária e na pressão perineal. Conclusão: Os procedimentos de EENM utilizados neste estudo foram igualmente eficazes no tratamento da IUE. Artigo registrado no Australian New Zealand Clinical Trials Registry (ANZCTR) sob o número ACTRN 12610000820000.

Palavras-chave: incontinência urinária de esforço; estimulação elétrica; saúde da mulher; fisioterapia; reabilitação.

Received: 02/02/2011 - Revised: 06/06/2011 - Accepted: 06/09/2011

\footnotetext{
'Master's degree in physical therapy student, College of Health Sciences, Universidade Metodista de Piracicaba (UNIMEP), Piracicaba, SP, Brazil 2Department of Obstetrics and Gynecology, School of Medicine, Universidade Estadual de Campinas (UNICAMP), Campinas, SP, Brazil

${ }^{3}$ Department of Biomechanics, Medicine and Rehabilitation of the Locomotor System, School of Medicine of Ribeirao Preto, Universidade de São Paulo (USP), Ribeirão Preto, SP, Brazil Correspondence to: Elaine Caldeira de Oliveira Guirro, Faculdade de Medicina de Ribeirão Preto, Universidade de São Paulo, Curso de Fisioterapia, Av. dos Bandeirantes, 3900, Monte Alegre, CEP 14049-900, Ribeirão Preto, SP, Brasil, e-mail: ecguirro@fmrp.usp.br
} 


\section{Introduction $: \because$.}

Urinary incontinence (UI) which is the involuntary loss of urine has high prevalence and represents a major public world wide health problem that can be associated with social isolation affecting quality of life ${ }^{1,2}$. It is estimated that approximately 200 million people around the world suffer from some form of $\mathrm{UI}^{2}$.

Stress urinary incontinence (SUI) is the most common type of UI and is defined as involuntary loss of urine that occurs when the intra-abdominal pressure and consequently the intravesical pressure exceeds maximum urethral closure pressure. Therefore, SUI commonly occurs during efforts, such as coughing, sneezing, laughing, jumping, running and lifting weight ${ }^{1,2}$.

The etiology of SUI is multifactorial with the most common cause being dysfunctions of the pelvic floor muscles (PFM). Therefore, several factors associated with pelvic floor muscles dysfunction have been reported to brisk factors for the condition such as pregnancy, types of delivery, parity, anatomical abnormalities of the urethra, nerve conduction disturbance in the PFM, genetic predisposition, iatrogenic causes resulting from surgery, age, estrogen level drop during menopause, and increased intra-abdominal pressure ${ }^{3,4}$. The normal function of the PFM is essential for supporting the pelvic visceras and maintaining urinary continence $e^{5,6}$.

Considering that the most common cause of stress incontinence is weakness of the PFM, available treatments, conservative or not, are aimed at rectifying this problem. However, surgical interventions have been reported to have low success rates and to be associated with postoperative complications and deterioration of clinical status. As a result of the poor outcomes of surgical treatments and with evidence suggesting positive results of conservative treatments with few adverse events, conservative treatment has been considered the first line of care for the treatment of SUI ${ }^{5}$.

The most common for of conservative treatment for stress urinary incontinence are PFM exercises, biofeedback, vaginal cones, electrical and magnetic stimulation. Neuromuscular electrical stimulation (NMES) aims to strengthen the PFM in an attempt to recover urinary continence mechanisms ${ }^{7.8}$. Although used successfully for over 25 years in clinical practice, there has been no consensus regarding the most effective treatment parameters and protocols of electrical stimulation. Previous studies evaluating the effectiveness of NMES reported varying protocols with regards to the location of the electrode (anal, vaginal or superficial), current parameters, time and duration of treatment ${ }^{8,9}$. The currents of low frequency $(\mathrm{LF}-50 \mathrm{~Hz})$ and low average frequency modulated (FM - $2000 \mathrm{~Hz}$, modulated at $50 \mathrm{~Hz}$ ) were predominantly used for the treatment of SUI in previous studies ${ }^{7,9-13}$.

Mediumfrequencycurrents spread rapidly throughthetissues arriving at the motor threshold easier and more comfortably than low frequency currents due to the lower impedance offered to theshort electrical pulses. Therefore, the use of medium frequencies allows for the use of a wider range of currents with recruitment of more motor units and penetration into deeper tissues without causing discomfort for the volunteers. As recommended, the maximum possible intensity for short periods of treatment should be applied, which is already commonly performed in clinical practice. At the same time, MF NMES stimulates nerves due to amplitude modulation which allows the current to develop the same electrophysiological responses in cells and tissues as that of therapeutic LF currents ${ }^{14-17}$.

Based on the aforementioned and given the lack of standardization of electrical parameters in the treatment of female SUI, the objective of this study was to evaluate two parameters of intravaginal NMES low and medium frequencies, for the treatment of women with SUI.

\section{Methods $: \because$.}

Twenty four volunteers were included in this randomized controlled trial; however, only 20 were included in our results as 4 patients failed to complete treatments. Patients' age was between 42 and 64 years $(55.55 \pm 6.51)$, body mass index (BMI) between 22.48 and $37.81 \mathrm{~kg} / \mathrm{m}^{2}$ (28.66 \pm 5.49$)$. All patients had a clinical diagnosis of SUI and urinary loss for at least three months.

The exclusion criteria was: urogenital prolapse grade III or higher ${ }^{18}$, urinary tract infection, instability of the detrusor muscle, cardiac pacemakers, devices implanted in the pelvis, vaginal inflammation/infections, pregnancy, intrinsic sphincter deficiency, use of hormone replacement therapy, pelvic or abdominal surgery within the last six months, cognitive impairment and non-attendance of the number of sessions provided.

The volunteers were randomly divided into two distinct groups, 10 women received NMES with a MF current (G1) and 10 women received NMES with a LF current (G2). The average age of group of G1 was $55.70 \pm 7.17$ years and of group G2 was $55.40 \pm 6.98$ years.

The study was conducted in accordance with the resolution 196/96 of the National Health Council (CNS). The research was approved by the Ethics Committee of the Universidade Metodista de Piracicaba (UNIMEP), Piracicaba, SP, Brazil, under Protocol 44/06, and all women signed an informed consent form. 
The initial evaluation was conducted through individual interviews using a questionnaire to verify personal data, lifestyle, personal history, medication, gynecological history and obstetric characteristics of the symptoms of urinaryleakage at the initial stages, quantity, frequency and circumstances of urinary loss, urinary disorders (nocturia, urgency, dysuria, etc.) and the need or use of guards (pads). Volunteers were instructed to register their daily urinary frequency using a diary for seven days before and after treatment.

A pulse generator 961 Dualpex $^{\circledR}\left(\mathrm{QUARK}^{\circledR}\right)$ with two independent channels were used for NMES. The volunteers were positioned in supine with the legs flexed and abducted. NMES was performed via intravaginal electrode previously cleaned and inserted with intimate lubricant gel in the vaginal canal for 20 minutes at maximum tolerable intensity twice a week for six weeks adding to a total of 12 sessions. The following electrical parameters were used: Group 1 (G1): medium frequency (MF) current, biphasic frequency of $2000 \mathrm{~Hz}$, pulse width of $100 \mathrm{~ms}$, time on: off 4:8 s, and modulation frequency of $50 \mathrm{~Hz}$; Group 2 (G2): low frequency (LF) current, biphasic, $50 \mathrm{~Hz}$ frequency, pulse width of $700 \mathrm{~ms}$, time on: off 4:8 s.

The perineal pressure was measured at six different times: before the first session (PRE), after the fourth (POST 4), sixth (POST 6), eighth (POST 8), tenth (POS 10) and twelfth (POST 12) NMESsession. The perineometry was performed with the equipment MyofeedbackPneumátco - PERINA 966-2, QUARK $^{\circledR}$ (ANVISA registration No. 80079190005), graded from 0 to $46.4 \mathrm{mmHg}$, and calibrated by the Office of Weights and Measures (IPEM). The probe was coated with urogynecologic sterile non-lubricated condom (brand Blowtex ${ }^{\circledR}$ ) and covered by intimate lubricant gel KY ${ }^{\circledR}$ (Johnson \& Johnson).

The test for PFM maximum voluntary contraction was performed with volunteers positioned in supine with hips flexion of approximately $60^{\circ}$ and knee flexion of approximately $45^{\circ}$. We conducted initial awareness training for the maneuvers to be performed for identification of PFM contraction. A four second maximum sustained contraction of the muscles was elicited with the aid of verbal commands ("squeeze, squeeze, squeeze") always given by the same researcher. Contraction of the PFM was considered valid only if simultaneous observable cranial movement of the perineum occured ${ }^{19}$. The procedure was repeated three times with an interval of $60 \mathrm{~s}$. All evaluations of the pelvic floor were made by the same investigator throughout the study.

An objective assessment of urinary incontinence was carried out using a 1 hour pad test, witch according to the study of Liebergall-Wischnitzer et al. ${ }^{20}$ provide similar results as subjective evaluation tools of urinary incontinence. The pad test was performed at: PRE, POST 6 and POST 12 NMES session.
To evaluate the severity of urinary incontinence, the results of the pad test were categorized according to the Laycock and Green ${ }^{14}$ criteria.

A visual analog scale (VAS) was used at PRE, POST 6 and POST 12 to subjectively evaluate the discomfort caused by urinary incontinence. The scale consisted of a $10 \mathrm{~cm}$ line ranging from "no discomfort" to "very uncomfortable".

\section{Data analysis}

The sample size was previously calculated based on averages and standard deviations of perineal pressure obtained from a pilot study. The result demonstrated the need to include 20 volunteers for a test power of $80 \%$ with alpha significance level of 0.05 (software GraphpadStatemate $2.0^{\circledR}$ ).

For analysis of data normality, we used the Shapiro-Wilk test, followed by the Friedman test for nonparametric data. For analysis of symptoms related to UTI, as well as the history of the volunteers the Fisher exact test and the Mann-Whitney test were used. The data recorded in the diary was analyzed using the Wilcoxon test and Mann-Whitney tests for within and between groups analysis, respectively. The intra-therapist agreement (within-session) for the PFM assessments was evaluated using the kappa statistic, considering negligible agreement for kappa between 0 and 0.2, median agreement between 0.21 and 0.4 , moderate agreement between 0.41 and 0.6 , substantial agreement between 0.61 and 0.8 , and almost perfect agreement between 0.81 and 1.0, according to the criteria of Landis and $\mathrm{Koch}^{21}$. A significance level of $5 \%$ was used for all data analysis. All statistical procedures were performed using Bioestat 4.0.

\section{Results $: \because$}

There were no significant differences $(p>0.05)$ of age and BMI between groups characterizing a homogeneous sample.

The intra-therapist agreement (within-session) for the PFM assessments was substantial with kappa of - $0.61^{21}$.

The average time from onset of complaints of stress urinary incontinence was not significant different $(p>0.05)$ between groups $(\mathrm{G} 1=6.50 \pm 7.95$ years and $G 2=7.20 \pm 6.03$ years . The average urinary frequency that was evaluated using a diary for seven days demonstrated urination of $6.80 \pm 1.72$ for G1 and 8.54 \pm 2.98 urination for G2 at PRE ( $>>0.05)$. A within group significant difference was observed between pre and post treatment values for G1 and G2, but no significant difference $(p>0.05)$ were found between groups at POST (G1 - 5.55 \pm 1.37 and $\mathrm{G} 2-5.80 \pm 2.00$ urination), demonstrating 
a reduced frequency of micturition after treatment in both groups.

The objective evaluation of urine loss (in grams) using the 1-hour pad test demonstrated similar average urinary loss at PRE for G1 and G2 ( $>0.05)$, indicating that both groups suffered from mild to moderate urinary incontinence according to the criteria of Laycock and Green ${ }^{14}$. There were statistically significant $(\mathrm{p}<0.05)$ within groups differences for the values of PRE and POST 12 for both groups. The amount of leakage in the 1-hour pad test for the within group differences for

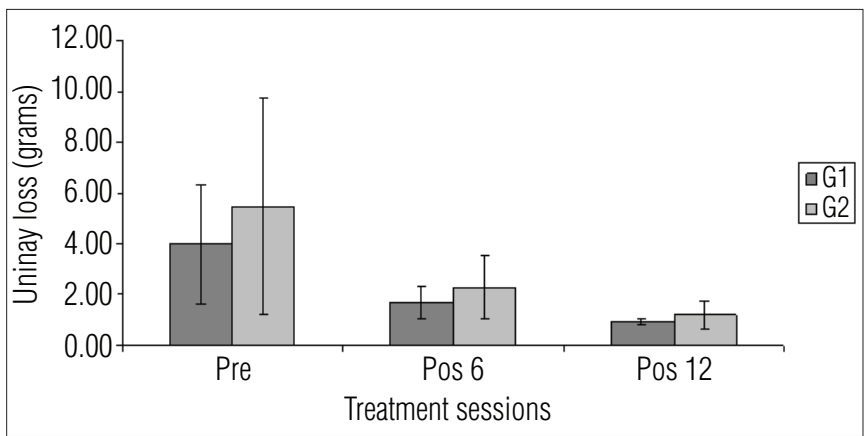

Figure 1. Pad urine loss of urine before the first test (PRE), after the sixth (POST 6) and twelfth session (POST 12) of NMES with medium frequency (G1) and low frequency current (G2).

Table 1. Distribution of the volunteers according to the classification of the severity of urinary incontinence categorized according to criteria of Laycock and Green ${ }^{14}$, before the first session (PRE), after sixth (POST 6) and twelfthsessions (POST 12) of NMES with medium frequency (G1) and low frequency current (G2).

\begin{tabular}{lccccccc}
\hline \multirow{2}{*}{ Classification } & \multicolumn{3}{c}{ G1 } & \multicolumn{3}{c}{ G2 } \\
& PRE & POS 6 & POS 12 & PRE & POS 6 & POS 12 \\
\hline Drought (lossless) & 0 & $90 \%$ & $100 \%$ & 0 & $40 \%$ & $100 \%$ \\
\hline Mild to moderate loss & $90 \%$ & $10 \%$ & 0 & $90 \%$ & $60 \%$ & 0 \\
\hline Severe loss & $10 \%$ & 0 & 0 & $10 \%$ & 0 & 0 \\
\hline
\end{tabular}

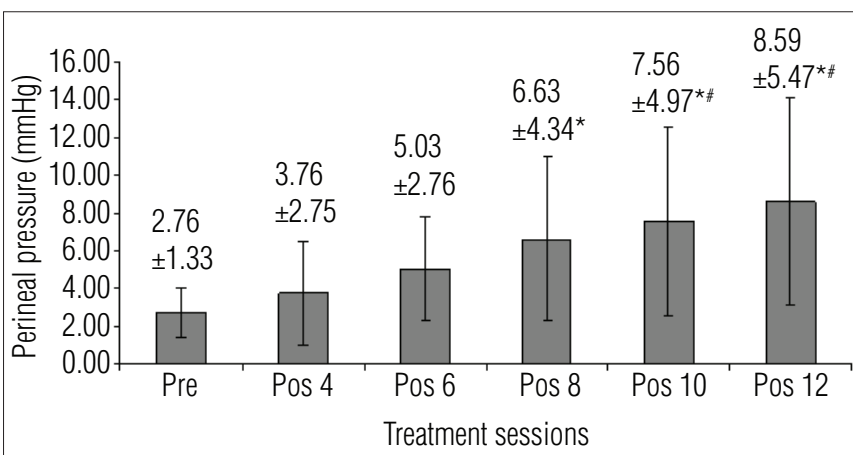

${ }^{*} p<0.05$ for PRE; ${ }^{\sharp} p<0.05$ to POST 4.

Figure 2. Perineal pressure $(\mathrm{mmHg})$ before (PRE), after fourth (POST 4), sixth (POST 6), eightieth (8 POST), tenth (POST 10) and twelfth sessions (POST 12) treatment with NMES medium frequency (G1).
PRE and POST 6 and between POST 6 and POST 12 were not significantly different $(p>0.05)$ for both groups. These results demonstrate that there was a gradual decrease in urinary loss in both groups with this decrease becoming significant only after the last treatment session. There was no significant difference ( $p>0.05$ ) in urine loss between groups at any of the follow-ups (Figure 1).

There were no significant difference ( $p>0.05$ ) between groups at PRE, POST 6 and POST 12 for the objective evaluation of urine loss according to the criteria of Laycock and Green ${ }^{14}$ (Table 1).

The mean degree of discomfort of the UI symptoms assessed using VAS was $7.4 \pm 1.8$ at PRE, $3.3 \pm 1.5$ at POST 6 and $0.6 \pm 0.7 \mathrm{~cm}$ at POST12 for G1 and $7.2 \pm 1.8 \mathrm{~cm}$ at PRE, $3.2 \pm 1.4 \mathrm{~cm}$ at POST6 and $0.5 \pm 0.4 \mathrm{~cm}$ at POST12 for G2. There were no significant difference between groups for any of the follow-ups ( $p>0.05)$. There were within group significant differences for both G1 and G2 between PRE and POST 12 ( $\mathrm{p}<0.05)$.

The perineal pressure was not signicantly different ( $p>0.05$ ) between G1 and G2. However, the within group comparisons were significantly different between PRE and POST 8, 10 and 12 and POST4 with POST10 and 12 for both groups (Figures 2 and 3 ).

\section{Discussion $: \because$.}

Amaro, Gameiro and Padovani ${ }^{5}$ observed reduction in voiding frequency of 7 to 5.5 micturition per day after treatment with LF intravaginal NMES current with the addition of perineal exercises 5 weeks after beginning of NMES in volunteers suffering from UI. Similar results were observed in this study where the average urination was $6.80 \pm 1.72$ at PRE and $5.55 \pm 1.37$ at POST treatment in G1 and $8.54 \pm 2.98$ at PRE and 5.80 \pm 2.00 urination at POST treatment in G2.

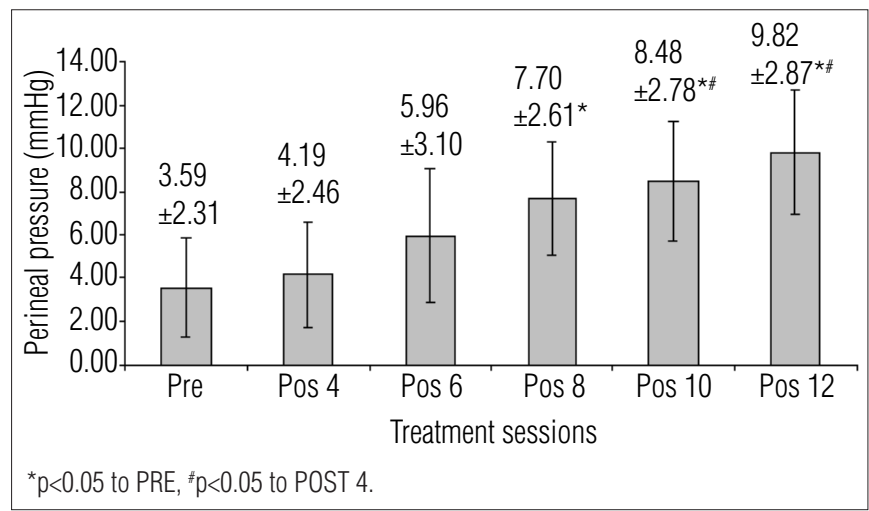

Figure 3. Perineal pressure $(\mathrm{mmHg})$ before (PRE), after fourth (POST 4), sixth (POST 6), eightieth (8 POST), 10 (POST 10) and twelfth sessions (POST 12) treatment with NMES low frequency (G2). 
In relation to the objective assessment of the amount of urine lost and the severity of symptoms assessed by the 1 hour pad test in both groups there was a decreased amount of urine lost and consequently an improvement in the degree of severity of UI over the six weeks of treatment. This data agrees with findings by Oláh et al. ${ }^{15}$ who compared the use of vaginal cones to the use of MF NMES current in a group of women with UI. After four weeks of treatment, $50 \%$ of volunteers in the cone group and $76 \%$ in the NMES group had improvements in the 1-hour pad test. Similarly, on the studies of Castro et al. ${ }^{22}$ and Santos et al. ${ }^{23}$ there were a reduction of urinary loss in the pad test in women with UI who underwent LF NMES, exercises for the PFM or vaginal cone therapy.

Laycock and Jerwood ${ }^{16}$ treated incontinent women with MF NMES current modulated at low and NMES placebo and found significant improvements in the values of the modified pad test among women who received the active current. Amaro, Gameiro and Padovani ${ }^{5}$ using NMES associated with perineal exercises found significant reduction in the amount of urine lost after treatment.

Parkkinen et al. ${ }^{11}$ using MF NMES current after an exercises series for the PFM associated with biofeedback to treat women with stress incontinence observed a significant reduction in urinary loss from a 1 hour pad test after four months of treatment and follow-ups of 12 months and 5 years. However, there was no significant difference between women who received PFM exercises associated to biofeedback and NMES from those who received PFM exercises only.

Sand et al. ${ }^{9}$ in a clinical double-blind study treated 52 women with SUI during 15 weeks divided into two groups: one using an equipment of active NMES at frequencies of $12.5 \mathrm{~Hz}$ and $50 \mathrm{~Hz}$ simultaneously and one of NMES placebo (SHAM). The reduction in urine loss during on the modified 20 minutes pad test in women with active devices was better than those from the SHAM group. Similarly, Yamanishi et al. ${ }^{24}$ found a significant reduction in urine loss on a 1 hour pad test in the group of active device compared with the SHAM device group. In the present study, all women from G1 and G2 were considered cured ${ }^{25}$ after six weeks of treatment, i.e. no urine loss. However, the studies of Luber and Wolde-Tsadik ${ }^{26}$ and Spruijt et al. ${ }^{27}$ using the pad test showed no significant difference in urine loss in women with SUI treated with NMES compared with the control group (placebo NMES) or Kegel exercises.

Richardson et al. ${ }^{13}$ observed significant improvement in VAS values after the use of LF NMES current either daily or on alternate days but with no difference between the two regimes. Miller et al. $^{28}$ aiming to determine the number of sessions necessary for a NMES treatment found a reduction in complaints of discomfort from 10 weeks of treatment. However, on the present study the complaints of discomfort had not yet significantly reduced after six weeks of treatment. Demirtürk et al..$^{29}$ noted improvement in signs and symptoms of stress incontinence after 5 weeks of treatment with 15 min of electrical stimulation, three times a week, but the parameters of electrical stimulation used were not clearly described.

In a study by Sand et al. ${ }^{9}$ the results of the VAS were significantly greater in volunteers who used an active device than from those who received a placebo (SHAM group). Laycock and Jerwood ${ }^{16}$ demonstrated a significant improvement in VAS after the application of NMES with an interferential current and no effect on the NMES group using placebo. The same was also described by Bø, Talseth and Holme $^{30}$ who compared women that underwent LF NMES current and a no treatment group.

The perineometry of PFM in this study showed significant growth after the eighth treatment session in both groups, confirming the results found in other studies ${ }^{5,30}$.

Sand et al. ${ }^{9}$ found a significant increase in perineal pressure among women who used active NMES compared to NMES placebo current. However, Amaro, Gameiro and Padovani ${ }^{5}$ found no statistical difference in perineal pressure among groups after one month of treatment, using a current of $4 \mathrm{~Hz}$ and pulse width of $0.1 \mu \mathrm{s}$.

Muscle contraction caused by NMES is directly influenced by amplitude and pulse width. Parkkinen et al. ${ }^{11}$ have recommended an interferential current with a frequency of $2000 \mathrm{~Hz}$, modulated at $50 \mathrm{~Hz}$ and a pulse width of $250 \mu \mathrm{s}$. Laycock and Jerwood ${ }^{16}$ have recommended frequencies of 35-40 Hz and a pulse width of $250 \mu$ s as effective and tolerable for women, while other authors have recommend a frequency of $50 \mathrm{~Hz}$ and pulse width of $300 \mu \mathrm{s}^{9,13}$.

$\mathrm{B} ø$ and Maanum $^{10}$ investigated whether the electrically induced contraction of PFM was similar to that of voluntary contraction. They used two NMES devices with different pulse widths (500 $\mu \mathrm{s}$ and $750 \mu \mathrm{s})$ and frequencies of $10 \mathrm{~Hz}, 20 \mathrm{~Hz}$ and $50 \mathrm{~Hz}$, which were matched, making five combinations of electrical parameters: $10 \mathrm{~Hz}$ and $750 \mu \mathrm{s}, 20 \mathrm{~Hz}$ and $750 \mu \mathrm{s}$, $50 \mathrm{~Hz}$ and $750 \mu \mathrm{s}, 10 \mathrm{~Hz}$ and $500 \mu \mathrm{s}$ and $50 \mathrm{~Hz}$ of frequency and $500 \mu$ s of pulse width. The results showed that only one woman reported feeling PFM contraction using $50 \mathrm{~Hz}$, pulse width of $500 \mu \mathrm{s}$ and intensity of $30 \mathrm{~mA}$. The other electrical currents caused discomfort, pain, sensations and movements from different physiological voluntary contraction. Moreover, the tolerance levels of intensity (on a scale of 0 to 10 where 0 is the "minimum" and 10 "maximum") were lower when subjects underwent the currents with pulse widths of $750 \mu \mathrm{s}$. 
Although rare, some studies reported adverse events such as pain, discomfort, irritation and vaginal infections with the use of NMES ${ }^{7,910}$. However, in this study, NMES was well received by the volunteers.

The current study presents a limitation regarding the lack of follow-up to access whether the improvements achieved with the different parameters of electrical stimulation would last in the long term.

Based on these results, it can be inferred that the LF and MF NMES were similarly effective in the treatment of female SUI, generating increased perineal pressure, reduced urinary loss and symptoms related to UI.

\section{References : :}

1. Abrams P, Cardozo L, Fall M, Griffiths D, Rosier P, Elmsten U, et al. The standardisation of terminology of lower urinary tract function: report from the Standardisation Sub-Committee of the International Continence Society. Neurourol Urodyn. 2002;21(2):167-78.

2. Contreras Ortiz 0 . Stress urinary incontinence in the gynecological practice. Int J Gyneacol Obstet. 2004;86 Suppl 1:S6-16.

3. Parazzini F, Colli E, Origgi G, Surace M, Bianchi M, Benzi G, et al. Risk factors for urinary incontinence in women. Eur Urol. 2000;37(6):637-43.

4. Silva APM, Santos VLCG. Prevalência da incontinência urinária em adultos e idosos hospitalizados. Rev Esc Enferm USP. 2005;39(1):36-45.

5. Amaro JL, Gameiro M00, Padovani CR. Treatment of urinary stress incontinence by intravaginal electrical stimulation and pelvic floor physiotherapy. Int Urogynecol J. 2003;14(3):204-8.

6. Lukban JC, Whitmore KE. Pelvic floor muscle re-education treatment of the overactive bladder and painful bladder syndrome. Clin Obstet Gynecol. 2002;45(1):273-85.

7. Herrmann V, Potrick BA, Palma PCR, Zanettini CL, Marques A, Netto Jr NR. Eletroestimulação transvaginal do assoalho pélvico no tratamento da incontinência urinária de esforço: avaliações clínica e ultra-sonográfica. Rev Assoc Med Bras. 2003;49(4):401-5.

8. Wyman JF. Treatment of urinary incontinence in men and older women: the evidence shows the efficacy of a variety of techniques. Am J Nurs. 2003;Suppl:26-35.

9. Sand PK, Richardson DA, Staskin DR, Swift SE, Appell RA, Whitmore KE, et al. Pelvic floor electrical stimulation in the treatment of genuine stress incontinence: a multicenter, placebocontrolled trial. Am J Obstet Gynecol. 1995;173(1):72-9

10. Bø K, Maanum M. Does vaginal electrical stimulation cause pelvic floor muscle contraction? A pilot study. Scand J Urol Nephrol Suppl. 1996;179:39-45

11. Parkkinen A, Karjalainen E, Vartiainen M, Penttinen J. Physiotherapy for female stress urinary incontinence: individual therapy at the outpatient clinic versus home-based pelvic floor training: a 5-year follow-up study. Neurourol Urodyn. 2004;23(7):643-8.

12. Rett MT, Simões JA, Herrmann V, Marques AA, Morais SS. Existe diferença na contratilidade da musculatura do assoalho pélvico feminino em diversas posições? Rev Bras Ginecol Obstet. 2005;27(1):12-9

13. Richardson DA, Miller KL, Siegel SW, Karam MM, Blackwood NB, Staskin DR. Pelvic floor electrical stimulation: a comparison of daily and every-other-day therapy for genuine stress incontinence. Urology. 1996;48(1):110-8.

14. Laycock J, Green RJ. Interferential therapy in the treatment of incontinence. Physiotherapy. 1988;74(4):161-8

15. Oláh KS, Bridges N, Denning J, Farrar DJ. The conservative management of patients with symptoms of stress incontinence: a randomized, prospective study comparing weighted vaginal cones and interferential therapy. Am J Obstet Gynecol. 1990;162(1):87-92.

16. Laycock J, Jerwood D. Does pre-modulated interferential therapy cure genuine stress incontinence? Physiotherapy. 1993;79(8):553-60.
17. Low J, Reed A. Eletroterapia explicada. $3^{\mathrm{a}}$ ed. Tamboé: Manole; 2001.

18. Bump RC, Mattiasson A, Bø K, Brubaker LP, DeLancey JO, Klarskov P, et al. The standardization of terminology of female pelvic organ prolapse and pelvic floor dysfunction. Am J Obstet Gynecol. 1996;175(1):10-7.

19. Bø K, Kvarstein B, Hagen RR, Larsen S. Pelvic floor muscle exercise for the treatment of female stress urinary incontinence: II. Validity of vaginal pressures measurements of pelvic floor muscle strength and the necessity of supplementary methods for control of correct contraction. Neurourol Urodyn. 1990;9(5):479-87.

20. Liebergall-Wischnitzer M, Paltiel O, Hochner-Celnikier D, Lavy Y, Shveiky D, Manor 0 . Concordance between one-hour pad test and subjective assessment of stress incontinence. Urology. 2010;76(6):1364-8.

21. Landis JR, Koch GG. The measurement of observer agreement for categorical data. Biometrics. 1977;33(1):159-74.

22. Castro RA, Arruda RM, Zanetti MR, Santos PD, Sartori MG, Girão MJ. Single-blind, randomized controlled trial of pelvic floor muscle training, electrical stimulation, vaginal cones, and no active treatment in the management of stress urinary incontinence. Clinics (São Paulo). 2008;63(4): 465-72.

23. Santos PF, Oliveira E, Zanetti MR, Arruda RM, Sartori MG, Girão MJ, et al. [Electrical stimulation of the pelvic floor versus vaginal cone therapy for the treatment of stress urinary incontinence]. Rev Bras Ginecol Obstet. 2009;31(9):447-52.

24. Yamanishi T, Yasuda K, Sakakibara R, Hattori T, Ito H, Murakami S. Pelvic floor electrical stimulation in the treatment of stress incontinence: an investigational study and a placebo controlled double-blind trial. J Urol. 1997;158(6):2127-31.

25. Freeman RM. What's a 'cure'? Patient-centred outcomes of treatments for stress urinary incontinence. Int Urogynecol J Pelvic Floor Dysfunct. 2007;18(1):13-8.

26. Luber KM, Wolde-Tsadik G. Efficacy of functional electrical stimulation in treating genuine stress incontinence: a randomized clinical trial. Neurourol Urodyn. 1997;16(6):543-51.

27. Spruijt J, Vierhout M, Verstraeten R, Janssens J, Burger C. Vaginal electrical stimulation of the pelvic floor: a randomized feasibility study in urinary incontinent elderly woman. Acta Obstet Gynecol Scand. 2003;82(11):1043-8

28. Miller K, Richardson DA, Siegel SW, Karram MM, Blackwood NB, Sand PK. Pelvic floor electrica stimulation for genuine stress incontinence: who will benefit and when? Int Urogynecol J Pelvic Floor Dysfunct. 1998;9(5):265-70.

29. Demirtürk F, Akbayrak T, Karakaya IC, Yüksel I, Kirdi N, Demirtürk F, et al. Interferentia current versus biofeedback results in urinary stress incontinence. Swiss Med Wkly. 2008;138 (21-22):317-21.

30. Bø K, Talseth $\mathrm{T}$, Holme I. Single blind, randomised controlled trial of pelvic floor exercises electrical stimulation, vaginal cones, and no treatment in management of genuine stress incontinence in women. BMJ. 1999;318(7182):487-93. 